\title{
Fertility and education among British Asian women: a success story of social mobility?
}

\section{Sylvie Dubuc*}

\begin{abstract}
High fertility among immigrant groups is often analysed as an expression of specific cultural factors and/or lower social status. I hypothesise that differences in educational attainment explain the fertility differentials across immigrant groups and generations in the UK. Building on previous work, and using household survey data and the Own-Child reverse-survival method, the paper presents for the first time total fertility and age-specific fertility estimates by broad categories of educational attainment for immigrant and second-generation British Pakistani, Bangladeshi, Indian, and Chinese women. I use these estimates to analyse how education influences childbearing across British Asian ethnic groups, and compare the fertility patterns of these groups to those of the whole UK population. High levels of educational attainment contribute substantially to the low overall fertility levels of Indian and Chinese women. Higher education also contributes to the lower fertility levels of the second-generation British Pakistani and Bangladeshi women relative to those of the immigrant generation. Some differences between groups remain after decomposing by educational level, which suggests that there are additional influencing factors. The results are discussed in the context of social theories on the incorporation of immigrants and minorities.
\end{abstract}

\section{Introduction}

In recent years, the body of research on childbearing among the daughters of immigrants in Europe has been growing (e.g. Mileski 2010; Scott and Stanfors 2011a, b; Dubuc 2012, 2016; Hamel and Pailhé 2015; Stichnoth and Yeter 2016; Kulu et al. 2017). Although many immigrants in Europe came from higher fertility regions, low levels of fertility are becoming increasingly common among immigrant

\footnotetext{
* Sylvie Dubuc, Department of Geography, University of Reading, Whiteknights, Reading, RG6 6AB, UK

Email: s.dubuc@ reading.ac.uk
} 
women. In the UK, the reduction in fertility across successive cohorts of immigrant women has occurred in parallel to the fertility transition in their country of origin (Dubuc 2016). In Germany, Stichnoth and Yeter (2016) found a strong effect of the country-of-origin fertility rates on the fertility outcomes of immigrants, and a weakened country-of-ancestral origin effect on the fertility outcomes of the second generation.

Beyond the observed trends, the social processes that underlie the childbearing patterns of the daughters of immigrants remain poorly understood. Adding to an emerging literature that focuses on the descendants of immigrants (e.g. Dubuc 2012; Kulu and Gonzalez-Ferrer 2014; Kulu et al. 2017; Andersson et al. 2017), this paper contributes to bridging this gap by (i) producing novel fertility estimates decomposed by educational attainment, and (ii) analysing how education influences fertility among British Asian women. In the UK and elsewhere, women's education is an important factor in fertility timing and levels (Berrington and Pattaro 2014). Building on previous work that estimated and analysed the fertility of immigrants and their daughters (Dubuc 2012, 2016), this study investigates to what extent the educational attainment levels of immigrant women and their daughters are associated with fertility patterns that differ from those of all British women. I hypothesise that differences in educational attainment explain differences in fertility across Asian immigrant groups and generations in the UK, including among the second generation of 'migrants'.

I compare the fertility patterns of the four predominant groups of British women of Asian heritage for which identification data are available. These four groups display different distributions of educational attainment and fertility levels, which allow us to study how ethnicity, education, and migration status combine to influence childbearing.

\subsection{Ethnic fertility differences and convergence in the UK}

Since the 1980s, an ethnicity variable has been included in UK censuses and surveys (see Appendix A1) in an effort to capture the growing diversity of the British population due to international migration (for details, see Dubuc 2016), ${ }^{1}$ and to investigate potential associated forms of discrimination. In the UK, ethnic fertility differentials are well documented, with Pakistani and Bangladeshi women having the highest total fertility levels (more than three children) and Chinese women having the lowest levels (fewer than 1.5 children) (e.g. Rees et al. 2008; Coleman and Dubuc 2010). Since the 1970s, the TFRs of the various ethnic groups have been converging (Dubuc and Haskey 2010). This trend is driven in part by the

\footnotetext{
1 These ethnic minority categories largely reflect the post-World War II migration waves (from the Caribbean, South Asian, and Chinese diasporas). Recent trends and the broader geographic origins of immigrants have contributed to the increase in the sizes of ethnic categories such as the broad 'Black African' ethnic group and those labelled as 'other' (i.e. Other White, Other Black, Other Asian, Other).
} 
decline in fertility across successive cohorts of immigrants in the UK (Dubuc 2016). While the reported ethnic minority populations in the UK have grown partly due to immigration, they have also expanded through natural increase. Compared to that of first-generation immigrant women, the total fertility of second-generation women in the UK tends to be closer to that of the national average and of the White British ethnic majority. Indeed, fertility among second-generation women of Indian heritage has even dropped slightly below the national average (Dubuc 2012). It is often assumed that intergenerational fertility convergence is a sign that immigrants are assimilating to the 'local' fertility behaviour (e.g. Milewski 2010; Stichnoth and Yeter 2016). The question of whether these fertility patterns are converging has been a main focus of quantitative research on immigrants and ethnic fertility. However, which benchmarks should be used and how the results should be interpreted are questions that continue to be debated. Moreover, the lack of knowledge about the processes that underlie these patterns have hampered advances in this developing theoretical debate.

\subsection{Fertility and educational attainment}

Women's educational attainment is generally seen as an important individual level factor in the number of children born to families within a population (e.g. Basu 2002), as well as in the differences in the timing of childbearing among women, with shifts towards later childbearing typically associated with higher educational attainment (Rindfuss et al. 1996; Mayer and Riphaln 2000; in the UK: Rendall et al. 2004; Berrington and Pattaro 2014). ${ }^{2}$ Globally, women with more schooling tend to delay childbearing and to have fewer children by the end of their reproductive period (e.g. KC et al. 2010 and references therein), although there is evidence that educational differences in fertility levels have been narrowing in some countries in recent years (e.g. in the USA: Pew Research Center 2015). In addition, it is assumed that for women with high educational attainment, the opportunity costs of childrearing are also high. This theory was initially proposed by Becker and Lewis (1973), and the reasoning was extended to women's emancipation (Van de Kaa 1987). Childbearing and childrearing are therefore analysed as factors that compete with and limit the income and the professional prospects of highly educated women.

In the UK, shifts towards later childbearing are also associated with higher educational attainment (Rendall et al. 2005). According to Berrington et al. (2015), the educational gradient in completed family size among women born between 1940 and 1959 was primarily attributable to differences in (i) the proportion of childless women and (ii) the ages of mothers at the first birth. Much less documented is the

\footnotetext{
2 In explaining the social classes of individuals, educational attainment has been analysed as an important factor mediating social background (Bourdieu 1974; Goldthorpe 1996). Differences in educational attainment may be used to approximate the social gradient within populations.
} 
role that the intersection of ethnicity and education plays in childbearing patterns. Preliminary work by Meurs et al. (2015) found that higher educational attainment was associated with reduced fertility among the children of immigrants in France and Germany. In an analysis of educational attainment among immigrants and the second generation in the UK, Modood (2005) found that, on average, secondgeneration Pakistani and Bangladeshi men and women had lower qualification levels than the 'White majority'. By contrast, members of the Chinese and Indian ethnic groups were found to have higher educational levels than the majority group (Heath et al. 2008; Lessard-Philips 2008; Dustmann and Theodoropoulos 2010). To help shed some light on the relationship between education and fertility, I describe the age patterns of childbearing and total fertility of the four main British Asian groups, and highlight their distinct educational attainment and fertility profiles. To analyse the combined effects of education and immigrant origin on fertility, I distinguish within these ethnic groups between immigrants and their descendants born in the UK, decomposed by their highest educational attainment level.

\subsection{Social theories of immigrants' incorporation}

While the assimilation theory, which seeks to explain the social trajectories of immigrants and their descendants, has been strongly criticised, it remains an important element of the theoretical framework used to analyse fertility in these groups. The socialisation hypothesis, which asserts that the values and norms at the childhood place of residence have a strong influence on later reproductive behaviour, together with Gordon's seminal work (1964) on the influence of the cultural and socio-economic environment at destination, underpin the linear assimilation theory. This theory posits that immigrants of different origins have varying levels of fertility because they are influenced by the reproductive norms and values in their place of origin and childhood environment. Socio-demographic differences between immigrants and the local majority diminish over time - and, importantly, from generation to generation - as these groups adapt to the destination country (Goldstein and Goldstein 1983; Stephen and Bean 1992). Consequently, the children of immigrants are expected to display a fertility pattern closer to that of the local norm than their immigrant parents and same-origin immigrant women of similar birth cohorts (i.e. contemporary first generation) would. The process may take more than one generation, but socio-economic and demographic assimilation to the general profile of the society of settlement should eventually result in full fertility convergence (Bean and Marcum 1978).

In response to criticisms of the linear assimilation theory and the role of particular effects and their interaction, many contemporary analysts of immigrants' fertility have developed concurrent hypotheses (e.g. Milewski 2010). Some of these hypotheses have, for example, examined how the migration process alters fertility levels and/or age patterns at childbearing, and how the social selectivity of immigrants influences their fertility (see Dubuc 2017 for details). 
The adaptation hypothesis focuses on how the duration of stay of immigrants leads to a convergence towards the fertility norms at destination (e.g. Adsera and Ferrer 2014). The socialisation hypothesis asserts that the fertility norms in the country/environment of socialisation represent the primary influence on the childbearing behaviour of immigrants. This theory would explain why, beyond the sole effect of the duration of settlement, the fertility patterns of those who migrated in early childhood are significantly closer to those of the population at destination than to those of women who migrated at older ages.

Intergenerational socio-demographic processes remain less understood. According to the socialisation hypothesis, the fertility levels of the second and successive generations are expected to converge towards those of the receiving country. This assumption is supported by evidence showing that the fertility levels of the descendants of early 20th century European immigrant waves to the USA rapidly converged with those of the native population (Morgan et al. 1994), a pattern that is generally interpreted as indicative of assimilation. In Europe, there is emerging evidence that the fertility trends of the children of immigrants from high-fertility countries are converging with those of the majority populations in the destination countries. According to the characteristic hypothesis, the persistence of differences in fertility levels between groups reflects differences in the social characteristics of their members over generations, assuming there is no strong degree of inherited cultural distinctiveness. For instance, in the USA, the role of female education in shaping fertility patterns and differences between immigrant groups and natives appears to be particularly large (e.g. Bean and Tienda 1987). But according to the assimilation theory, such social differences may be expected to fade over time in the absence of strong and persistent cultural distinctions.

The causal link formulated at the origin of the linear assimilation theory between cultural and structural assimilation processes, and, later, their co-occurrence, have been strongly criticised. In an attempt to reconcile these dimensions, the segmented assimilation theory (Portes and Zhou 1993), which posits that various groups may assimilate to various socio-economic strata of a society, adds an ethno-cultural dimension to the process of the incorporation of immigrants and their children into the society of settlement. For instance, immigrants may benefit from community solidarity and supportive shared values that nurture upward social mobility.

An early critique of the linear assimilation theory was based on the observed intergenerational decline in fertility among the middle and upper classes of the Jewish American community - and, later, among the higher segments of the Black and the Japanese-American communities in the US - to levels below those of white Americans of similar socio-economic positions. In response to this divergence from the expected intergenerational fertility convergence, Goldscheider and Uhlenberg (1969) proposed the minority status hypothesis. According to this theory, because of a perceived minority status penalty, and in the absence of pro-natalist norms, individuals and families have fewer children in order to facilitate their upward social mobility, possibly until full assimilation is achieved. 
Looking at fertility differentials of women of Asian heritage by educational attainment and country of origin, I hypothesise that differences in education can explain fertility differences across migrant groups and generations in the UK. The findings are discussed within the theoretical framework presented above notably, the selectivity of immigrants, their characteristics, and the socialisation hypotheses relevant to both immigrant and second-generation women - as well as within the framework of the segmented assimilation and minority status theories.

\section{Data and methods (LFS-OCM)}

UK birth registration data by country of origin are available for some immigrants, but these records do not specify the mothers' educational attainment, and do not identify the UK-born mothers who have immigrant parents. Thus, I used an indirect method, which was extensively presented and assessed in Dubuc (2009), that relies on household Labour Force Survey data (LFS 2002-2010) together with the reversesurvival own-children method (OCM). In this way, I was able to obtain a satisfactory sample size for estimating the fertility of sub-population/minority groups (for details, see Dubuc 2009). This method was used in previous work to produce TFRs and ASFRs by ethnicity and generation in the UK (e.g. Dubuc 2012, 2016). Here, these estimates are updated and further split by educational attainment.

Because information on the country of birth of the parents of adult respondents is not available in the LFS, information on the (self-defined) ethnicity and the country of birth of household members was used to approximate the second generation. UKborn women of Asian heritage and of reproductive ages (overwhelmingly below 40 years old) represent the second generation in the UK. ${ }^{3}$ As the daughters of earlier waves of Asian immigrants are likely to report the same ethnicity as their parents, ${ }^{4}$ I combine ethnicity and country of birth to distinguish between the women who were born in the UK and the women who were born overseas. Using this approach, I was able to distinguish between the first (immigrant) and the second (UK-born)

3 The age structure of non-White ethnic minority UK-born women is presented in Dubuc (2016). In the most recent surveys, children and teenagers of the third generation cannot be distinguished from those of the second generation.

4 In Britain, ethnic categories are largely defined according to a combination of race (as a social construct) and geographic origin (country or region of origin). Although ethnicity is self-defined by respondents in censuses and in surveys, these responses are guided by predefined categories. Jivraj and Simpson (2015) found that the ethnicity reported by each respondent in the censuses changed little across his or her life course, especially among the Chinese ethnic group and among groups identified by a single country (British Indian, Bangladeshi, and Pakistani groups). In addition, the racial structure of the ethnic categories (e.g. Asian or British Asian) is likely to favour similar self-reporting between the generations of the parents and the children (Dubuc 2016). This pattern may, however, mask heterogeneity in self-identity and a sense of belonging. Thus, the validity of defining these ethnic categories as social groups could be questioned. 
generations Asian women in the UK. For simplicity, the terms UK-born and second generation are used interchangeably for the analysed ethnic groups throughout the text. Accordingly, foreign-born women are identified as the immigrant generation.

As the sample size is critical, Household LFS data 2001-2010 (April-June quarters) were pooled across years. This resulted in an increased sample size of 328,046 women who were aged 15-63 at the time of the survey. Based on this sample, I produced period fertility measures for women aged 15 to 49 (1987-2010) split by ethnicity, by generation in the UK, and by educational attainment. Children were linked to their mothers using the household relationship matrix that links individuals within a household in each survey, as this approach has been shown to provide the most accurate child-mother linkage (see Waller et al. 2014 for details on the relationship matrix). To minimise the risk of an undercount, only children up to 14 years old were considered, because older children are at increased risk of living outside their mother's household (see below and Dubuc 2009, 2012). Children and women were reverse-survived up to 14 years prior to the survey, which made it possible to estimate births counts by the age of the mother and fertility rates by the single years of age of the women. ${ }^{5}$ As a result, each survey produced 15 consecutive years of estimates. The overall fertility estimates derived from successive surveys were produced for the period 1987 to 2010, which resulted in 190,960 births and a total of 3,629,310 woman years. After disaggregation by ethnicity, generation in the UK, and educational attainment, overall fertility estimates are presented for the 1987-2010 period only due to sample size limitations. In addition, fertility estimates derived from earlier LFS surveys (as presented in Dubuc 2012) were used to analyse the intergenerational changes in fertility in Figure 1, and to discuss the results. Immigrant women who were aged 15-49 in the earlier period (1965-1979) were used here as the proxy parent generation of the second-generation (UK-born) women of fertile ages over the 1987-2010 period. This allowed for an average gap of 26 years between the two generations.

Women were classified according to their highest educational qualification. The qualifications were grouped in three main categories: General Certificate of Secondary Education (GCSE; typically obtained at around age 16) and below, A-level, and higher education/degree. Total fertility (TFR) and age-specific fertility rates (ASFR) were produced. The women were then identified by their ethnic group, by whether they were foreign-born or UK-born, and by their highest educational level. Descriptive counts of women by parity are also provided for women aged 30 to 35 . It was not possible to estimate the children ever born to women over age 35 by parity because the fertility histories of the female respondents were not provided in the survey. Instead, their fertility was indirectly estimated using the reverse-survival method described above. Censoring at age 35 minimised undercounts of births, as older children may have no longer been living in their mother's household at the

\footnotetext{
5 For instance, a woman aged 25 with a child aged five in a 2005 survey would count as one birth to a woman aged 20 in 2000.
} 
time of the survey. Empirical evidence shows that most children live with their mother up to age 15. If anything, this risk of children being undercounted is likely to result in a slight underestimation of the family size of less educated women, who tend to have their children at younger ages. Given this limitation, the analysis cannot provide information on completed fertility. Instead, the results reflect the age patterns of childbearing based on a comparison of the differences in cumulated fertility up to age 35 across groups of women. ${ }^{6}$

In line with findings for France (Toulemon 2004) and for the Hispanic immigrants in the USA (Parrado 2011), Dubuc (2012) reported for the UK that the fertility of immigrant women was especially low prior to migration, and high after their move. Among immigrant women in the UK, the fertility peak is commonly observed at five to six years after migration (Robards and Berrington 2016). It is increasingly recognised that because of the migration effect on the tempo of fertility, there is a risk of overestimating immigrants' total fertility when period TFR calculations are based solely on birth registrations at destination (e.g. Toulemon 2004; Sobotka and Lutz 2009; Parrado 2011). One advantage of the LFS-OCM method applied here is that it minimises the risk of overestimating the total fertility of immigrants due to the aforementioned migration tempo effect, since the counts of women and children are not truncated at the date of arrival in the UK. Thus, it is possible to take into account a pre-migration fertility history ${ }^{7}$ of up to 14 years for the most recent migrant women; i.e. women who are most likely to experience post-migration childbearing 'recuperation'.

\section{Results}

\subsection{Fertility of British Asian women and intergenerational changes}

Figure 1 shows for the four main British Asian groups the total fertility (TFR) ${ }^{8}$ of (1) immigrant women aged 15-49 in 1965-1979; (2) immigrant women aged

\footnotetext{
$6 \quad$ The age structure of the second generation is still relatively young (Dubuc 2016). Even if we had the full fertility history data for these women, small sample sizes would have limited the significance of the cohort completed fertility estimates.

7 The impact of children left behind in the country of origin on LFS-OCM fertility estimates for immigrants was estimated to be very small; overall, only $0.2 \%$ of the children arrived more than four years after their mother (see Dubuc 2012).

8 Period total fertility rate (TFR) is the total number of children women would have if they were experiencing the age-specific fertility of women aged 15 to 49 at the time of measurement throughout their reproductive ages. Such a measure is susceptible to 'tempo' effects. Cohort completed fertility provides an accurate measure of the number of children women effectively have, but this indicator can obviously only be obtained for cohorts of women who have completed their childbearing. The TFR is computed as the sum of age-specific fertility rates (ASFRs). ASFR is the ratio of births per woman (or per 1000 women) of a particular age; typically, single-year or five-year age groups are used.
} 
Figure 1:

Intergenerational changes in the TFR by selected ethnic groups, 1970-2010

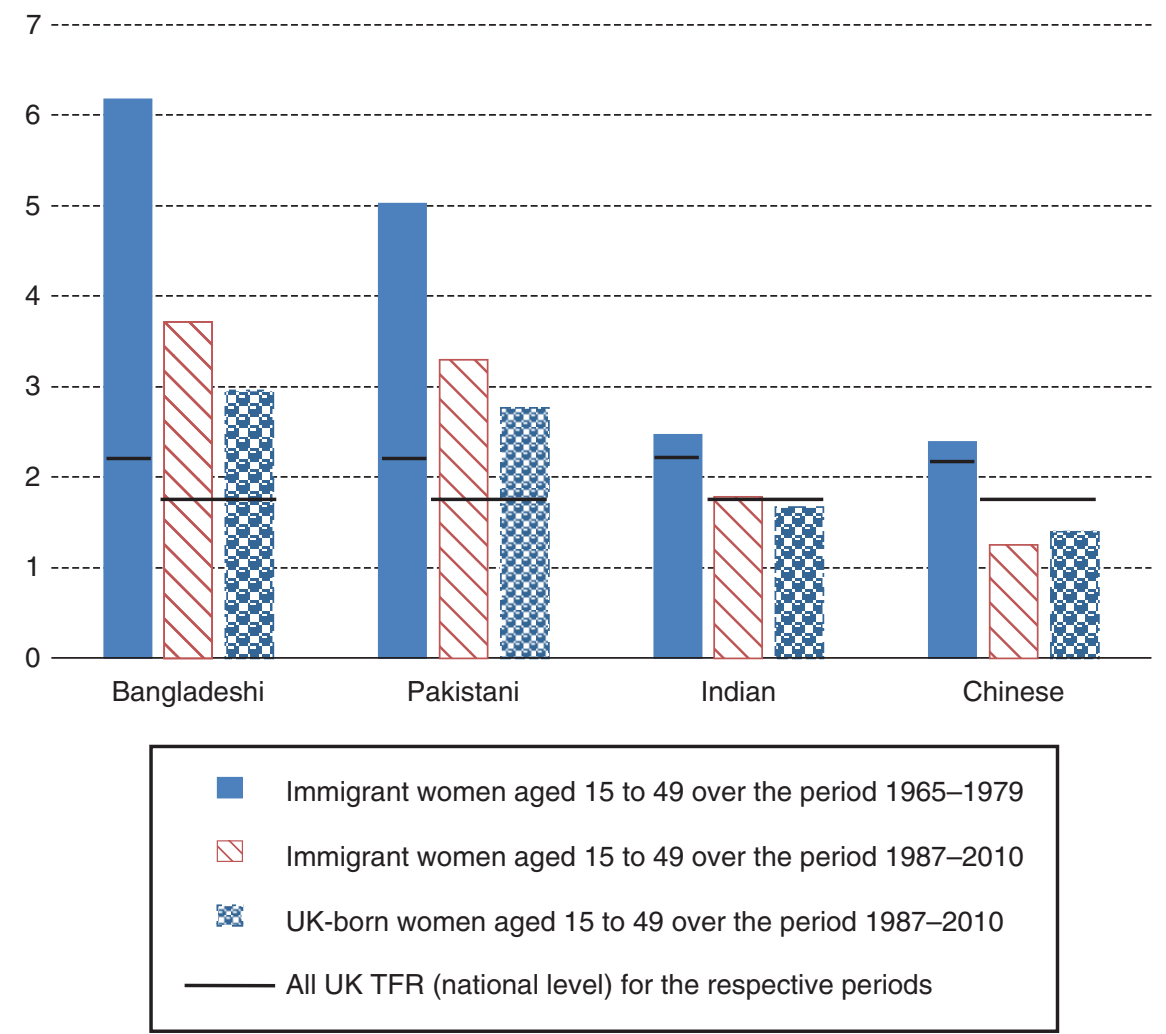

Note: Within ethnic minority groups, women in the earlier period (1965-1979) may stand for the proxy parent generation of the UK-born generation of women aged 15-49 in the 1987-2010 period. The overall UK TFR was 2.3 in the earlier period, and was 1.78 over the 1987-2010 period.

Sources: LFS-OCM author's calculations; Data for the South Asian groups published in Dubuc 2012 are updated here up to 2010 and are augmented with results for the Chinese women group. Counts of women are detailed in Appendix A2.

15-49 in 1987-2010 (called 'contemporary' immigrants); and (3) UK-born women of the same ages as the second group. In previous work (Dubuc 2012), I found a strong decrease in total fertility across successive cohorts of South Asian immigrant women (groups 1 and 2) and across successive generations in the UK (groups 1 and 3). In addition, Figure 1 shows a reduction in fertility over time across successive generations of Chinese immigrants. The trends in fertility among South and East Asian immigrants are generally consistent with the fertility reduction in their country of origin. Over the past two decades, fertility among Indian immigrants has declined to a level only slightly higher than the UK average, and has fallen below the national average among second-generation women. Starting from very high 
levels in the 1970s, total fertility among Pakistani and Bangladeshi immigrants has decreased sharply over time, especially among second-generation women; however, the fertility levels of this group are still above the UK average. Fertility has fallen well below the national average for both the contemporary immigrant and the UKborn generations of Chinese women; this group had the lowest TFR among all of the ethnic categories in the UK (below 1.4). Indeed, the fertility of contemporary Chinese immigrants deviates further from the UK-wide TFR than that of secondgeneration British Chinese women. We now turn to the educational attainment of women, exploring how it combines with fertility and whether it accounts for differences across ethnic groups and generations in the UK.

\subsection{Educational attainment of the British Asian women}

Can the very low fertility of Chinese women and the lower fertility of the young second generation of British South Asian women be explained by their educational attainment? Echoing the NOMIS report ${ }^{9}$ which showed that the majority of the UK population are not going to university, there is evidence that about $40 \%$ of UK women aged 25-29 between 2001 and 2010 had a degree (Source LFS 2010-2010), and that another $40 \%$ of these women were in the lower qualification group of GCSE or below. It thus appears that the distribution of educational attainment was quite polarised among women in the UK over the 1987-2010 period.

Figure 2 shows that of the ethnic groups studied, the Pakistani and Bangladeshi group had the largest share of women with lower qualifications, although this share was closer to the UK average for women of the second generation. In addition, while just 35\% of second-generation Pakistani and Bangladeshi women aged 25-29 over the study period had a degree, more than $50 \%$ of their British Indian counterparts and the vast majority of their British Chinese counterparts had a degree. In the past, the UK-born generation of women of Chinese ancestry aged 25-29 had slightly higher qualifications on average than the Chinese immigrant women (Figure 2). Consistent with reports of recent waves of highly educated immigrants from China (and from India to a lesser extent), the estimates for 2001-2010 suggest that this pattern no longer held in the most recent period. Educational attainment was also slightly higher in the recent cohorts of young immigrants from Pakistan and Bangladesh, but remained distinctly below the average level for all women in the UK. ${ }^{10}$

\footnotetext{
9 The report can be accessed at http://www.nomisweb.co.uk/reports/lmp/gor/2092957698/report. aspx\#defs.

10 For instance, $60 \%$ of women from Pakistan and Bangladesh who were aged 25-29 between 2001 and 2010 were in the lower educational group (GCSE and below).
} 
Figure 2:

Percentage of immigrant and second-generation Asian women aged 25-29 over the 1987-2010 period with GCSE or below as their highest qualification

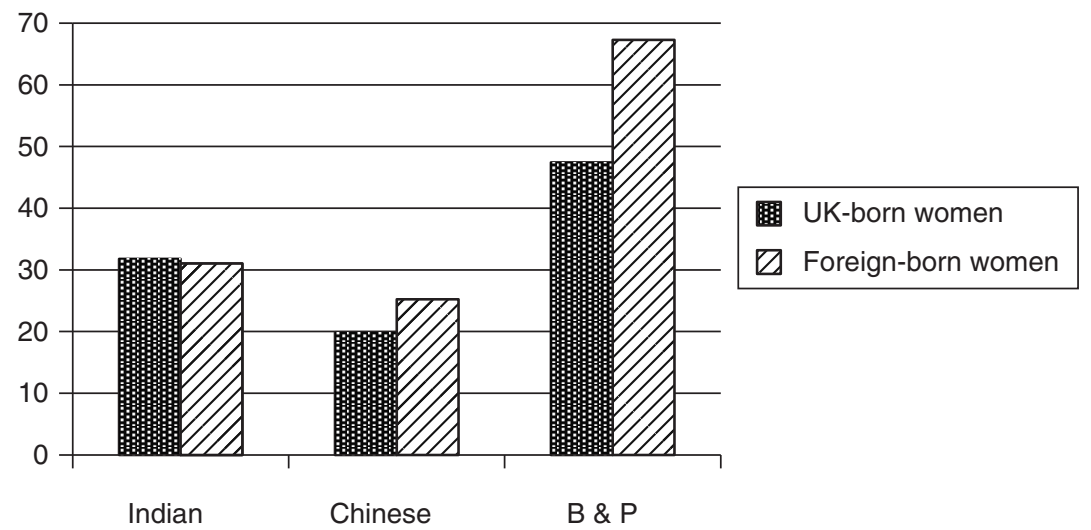

Note: GCSE and below = NVG2 equivalent or below; A-level = NVG3 equivalent; Degree = NVG4 equivalent; B\&P: Bangladeshi and Pakistani.

Source: LFS-APS 2001-2010. Counts of women used to estimate fertility by education (in Figures 3 and 4).

\subsection{Fertility, education, and generation in the UK}

I decomposed the fertility estimates presented above by women's educational attainment. Looking at all women in the UK, the results show that higher educational attainment was associated with lower period total fertility, and that this relationship varied little over time. ${ }^{11}$ Having a higher level of education was also found to be closely associated with later childbearing. These results are consistent with studies of cohort fertility in the UK (Berrington et al. 2015; Ní Bhrolcháin and Beaujouan 2012) and elsewhere (e.g. Rindfuss et al.1996; Mayer and Riphaln 2000).

How do these fertility differences by education apply to immigrant and minority ethnic groups? TFRs and ASFRs split by ethnicity and education are shown in Figures 3 and 4, respectively (due to sample size limitations, the A-level and the degree categories are combined in Figure 4). Consistent with the data for all women living in the UK, delayed childbearing and lower fertility were found to be closely associated with higher educational attainment among British Asian women. In other words, the differences in fertility levels and timing showed consistent educational gradients across the British Asian groups (Figures 3 and 4).

11 For instance, in 1991-1994, the TFR ranged from 2.10 for women with lower education to 1.49 for those with a bachelor's degree or higher. In 2003-10, their estimated TFR was 2.19 and 1.57, respectively. (Source: author's calculations using LFS-APS data 2001-2010.) 
Figure 3:

TFR by highest educational qualification of the women and selected ethnicity (1987-2010)

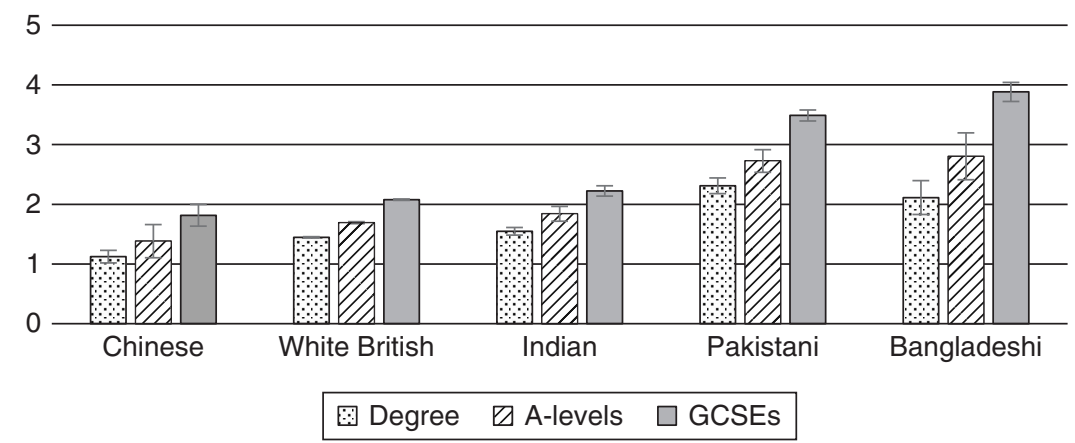

Note: The results are similar for all women in the UK and for the White British group representing the vast majority ethnic group in the UK.

Source: LFS 2001-2010. 95\% confidence intervals for sub-groups are shown.

Beyond these commonalities, I observed some differences across groups. When decomposing the TFRs and the ASFRs by broad qualification levels, I was 'controlling' for compositional differences in education across groups. If education level 'explained' all the differences in fertility between immigrant and ethnic groups, the fertility rates decomposed by educational levels should have been similar across groups in Figure 3. Indeed, the TFRs and the ASFRs of immigrant and secondgeneration Indian women with A-level or higher qualifications were similar to the national patterns for the whole UK. However, the fertility of both generations of British Indian women in their twenties with the lowest educational level (GCSE or below) remained slightly above the national average.

In contrast with the fertility levels of the British Indian women, the fertility levels of the British Chinese women remained lower than those of all British women for the three educational groups (Figure 3), especially for women under age 30 (Figure 4). The educational composition of first and UK-born generations of Chinese women did not fully account for their very low total fertility (Figure 4). In the case of British Pakistani and Bangladeshi women, fertility levels decomposed by educational attainment remained above the levels for all British women (Figures 3 and 4). This suggests that in addition to educational composition, other factors contributed to their higher fertility. Interestingly, the deviations from the national levels were smaller for women of the second generation (Figure 4b) for both educational attainment groups.

Focusing on women aged 30 to 35, Figure 5 shows the distribution of the number of children by educational attainment for all UK women (national level) and within British Asian groups. Because the fertility and education patterns of Pakistani and 


\section{Figure 4:}

ASFRs and TFRs of the main British Asian women groups by highest educational qualification (1987-2010)

a) Pakistani and Bangladeshi women: total

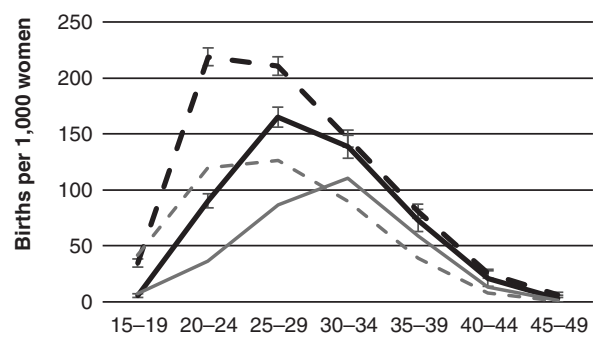

c) Indian women: total

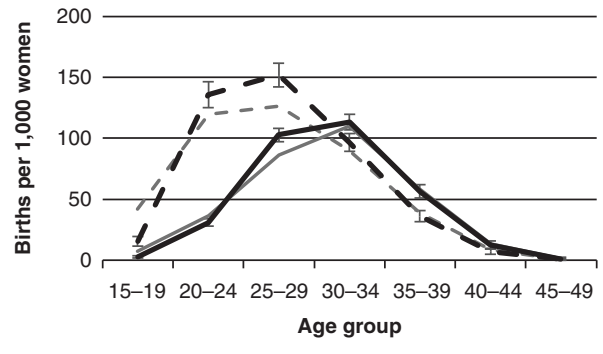

e) Chinese women: total

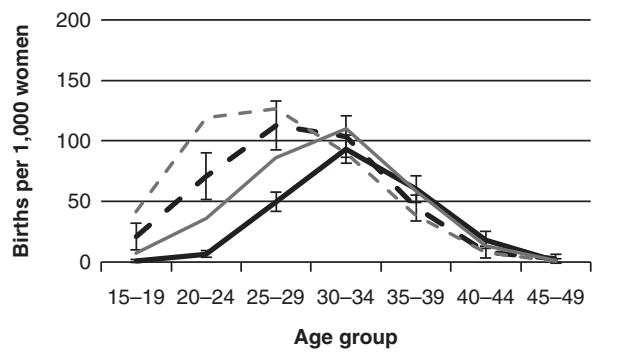

- - GCSEs / equivalent / No qualifications

- A-level / Degree

- - - GCSEs and below_All UK women

— A level and above_All UK women

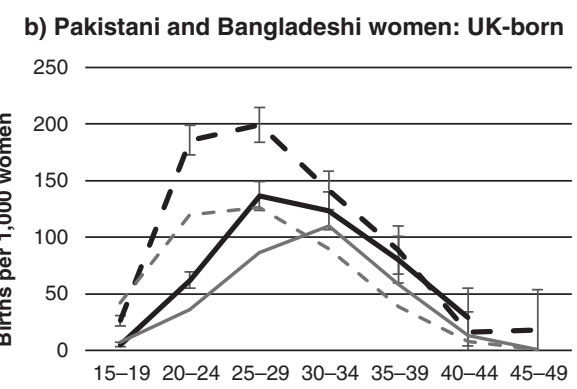

d) Indian women: UK-born

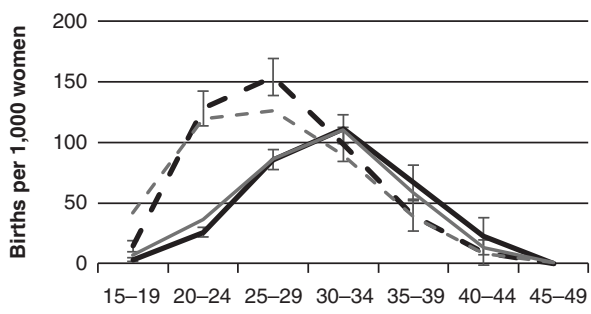

Age group

f) TFRs

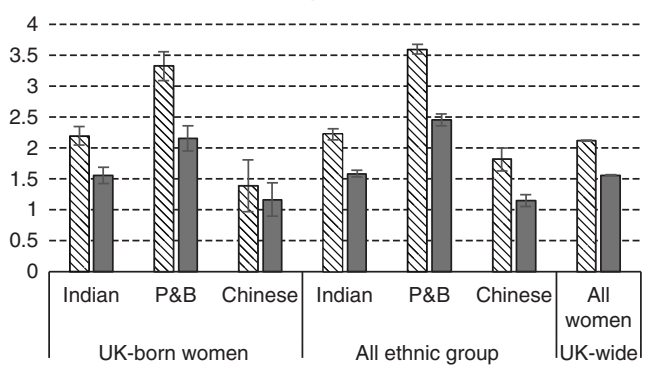

\begin{tabular}{|l|l|}
\hline GCSEs & $\square$ Degree \& A-levels
\end{tabular}

Note: The ASFRs for the UK-born Chinese are comparable to the patterns presented here, but the data are not shown due to large confidence intervals. 95\% confidence interval are shown.

Source: LFS 2001-2010.

Bangladeshi women were relatively close, I analysed the two groups together to increase the sample size and distinguish between immigrant and second-generation women. 'Two children' was the mode, particularly among UK women in their early 
Figure 5:

Distribution (\%) of women aged 30 to 35 at the time of the survey by parity, 1990-2010
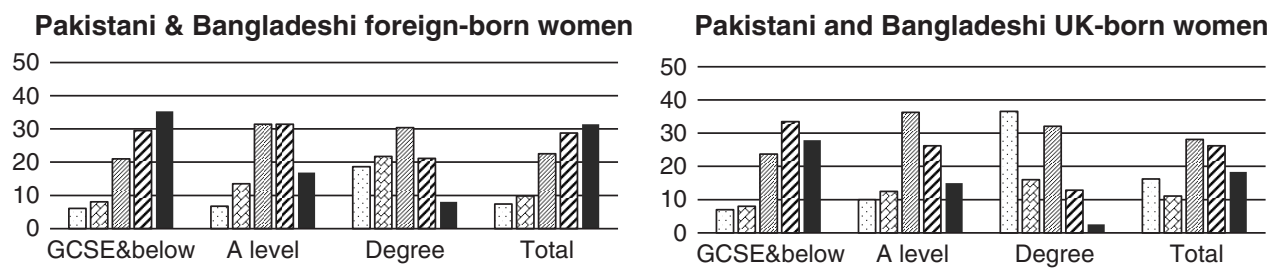

Indian foreign-born women

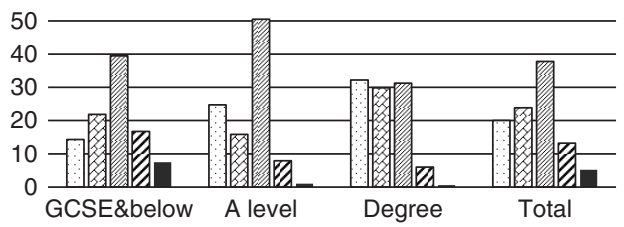

All women
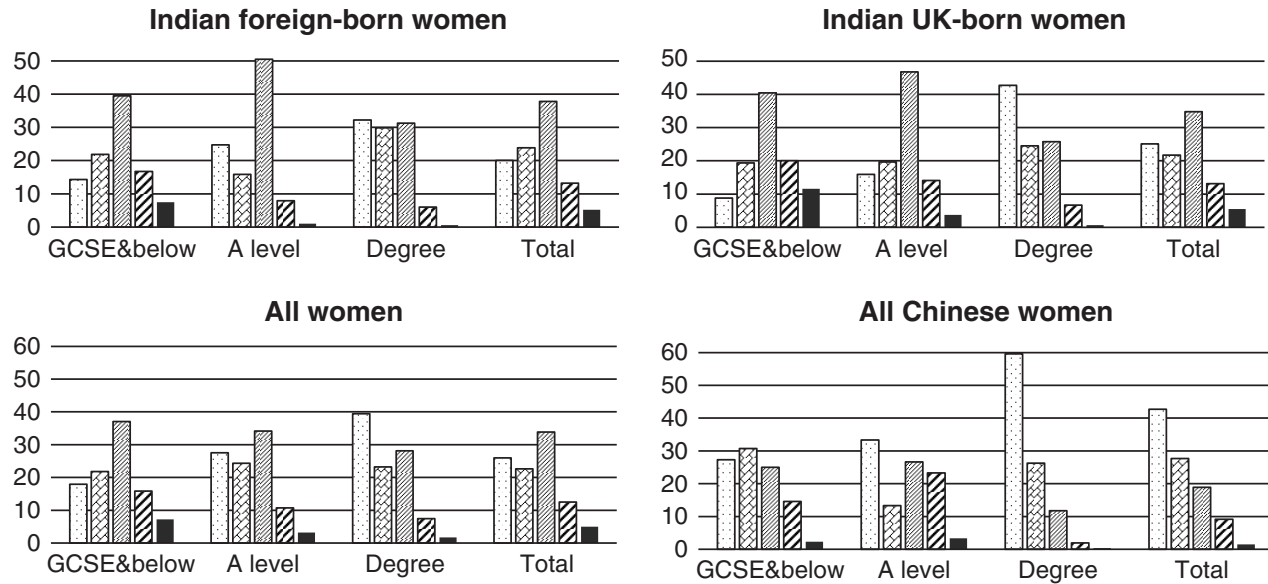

All Chinese women

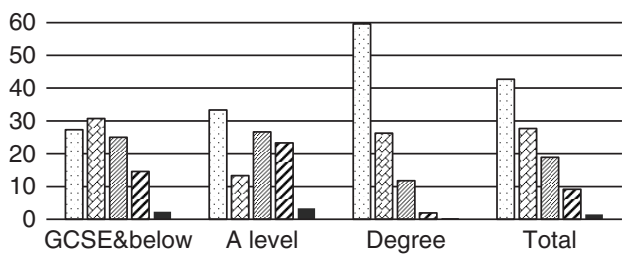

$\square 0 \quad \square 1 \quad \square 2 \quad \square 3 \quad \square 4+$

Note: Sample size: 108,247 (all UK) women aged 30-35, including Pakistani \& Bangladeshi women: 1533 foreignborn and 523 UK-born, Indian women: 1803 foreign-born and 707 UK-born, Chinese women: 545 (466 foreign-born and 79 UK-born).

Source: LFS 1990-2010.

thirties with low to medium educational attainment. Among women with a degree, being childless was the most common status overall. Although the women in this study have not completed their reproductive lives, these observations are consistent with the postponement of childbearing by highly educated women.

As expected, the results show that having a low level of education was associated with having more children overall across the migrant/ethnic groups. For instance, about 35\% of immigrant Pakistani and Bangladeshi women with GCSE or lower qualifications had four or more children by ages 30-35 over the 1990-2010 period. This share was much lower for women of this ethnic group with A-level qualifications or higher (below $10 \%$ for women with a degree). Having four or more children was the most common scenario among immigrant Pakistani and Bangladeshi women aged 30-35, but having two children was the most common 
scenario among women of the second generation. In contrast, having four children was rare among lower educated Chinese women; and having no children at ages 30-35 was by far the most common scenario among the Chinese ethnic group (60\% of women with a degree). Among British Indian women, especially those of the second generation, the average parity distribution was in line with that of the UK. The findings also indicate that among second-generation Indian, Pakistani, and Bangladeshi women aged 30-35 (Figure 5), those with a degree were more likely to have remained childless than their counterparts who were born overseas (immigrants).

\section{Discussion}

\subsection{Education: a compositional effect}

Levels of educational attainment have been particularly high among British Indian and Chinese women, and have increased among second-generation Pakistani and Bangladeshi women. Having a high educational level was found to contribute similarly to lower and delayed fertility among both immigrant groups and native women. Consequently, the high average qualification levels of British Chinese and Indian women, which are well above the national average, largely explain their low fertility. By contrast, immigrant Pakistani and Bangladeshi women still have low average qualification levels and relatively high fertility. Although full convergence has not been achieved, second-generation British Pakistani and Bangladeshi women have educational attainment and fertility levels that are closer to the UK average than those of their first-generation migrant counterparts of similar cohorts. ${ }^{12}$

In summary, and as hypothesised, differences in educational attainment contribute to the fertility differences observed across immigrant groups and generations in the UK. Consistent with the findings at the national level (e.g. Ní Bhrolcháin and Beaujouan 2012), I found that young women with high levels of educational attainment have lower fertility rates and higher rates of childlessness. Because the data used in this study did not allow for the analysis of cohort completed fertility, ${ }^{13}$ whether young British Asian women with higher educational levels

12 On average over the study period, the TFRs of second-generation Pakistani and Bangladeshi women were, respectively, 55\% and 65\% higher than the UK-wide TFR. But for immigrant women from Pakistan and Bangladesh, the TFRs were, respectively, $85 \%$ and 105\% higher than the UKwide TFR.

13 The reverse-survival method used to overcome the absence of fertility history in the LFS datasets does not allow for the computing of cohort completed fertility data, and thus for the analysis of the influence of tempo effects due to expanding education on the total number of children ever born. Although the current sample size remains small, novel UK longitudinal data sources (Longitudinal Study and Understanding Society) with larger sample sizes over time are promising for future analyses of cohort fertility. 
have simply delayed childbearing, and will have completed fertility above the current period TFR levels, remains unclear. Recent evidence has shown that highly educated women in the UK who delayed childbearing did not fully compensate at later ages, leaving most highly educated women with fewer children and higher levels of childlessness than less educated women (Berrington et al. 2015). Sample size remains an issue, but new UK longitudinal data would allow us in the future to analyse cohort completed fertility by migrant group. Nonetheless, the higher incidence of childlessness at ages 30-35 observed among second-generation Indian, Pakistani, and Bangladeshi women than among their immigrant counterparts suggests that - consistent with the socialisation hypothesis - there is a contextual effect in the timing, if not the level, of childbearing.

Over the last decade in India, the TFRs of women with a secondary education or above have been below the replacement level. ${ }^{14}$ Indian immigrants largely come from the Indian urban middle class, a group that has been leading the fertility transition in India. Selectivity of migration can explain the high educational attainment of these immigrants and the closeness of their period TFR to the UK average. In contrast, immigrants from Pakistan and Bangladesh are more likely to be of rural origin and less educated. The very low fertility among the more recent immigrants from China may be partly explained by a change in the 'selectivity' of Chinese immigrants. They are increasingly students and highly educated young professionals from mainland China, whereas earlier waves of post-World War II Chinese migrants were mainly from Hong Kong, and were more likely to have a peasant background.

\subsection{Beyond educational attainment, some unexplained differences across groups remain}

While the fertility levels of highly educated immigrant and second-generation British Indian women are very similar to the UK average, the fertility levels of those with lower educational attainment remain slightly above the UK average. If educational composition alone was responsible for fertility differences, we would expect to have found that the overall TFR of British Indian women was lower than the UK average, and even more so for the second generation. After accounting for educational composition, the analysis showed that for all educational groups, fertility remains above the UK average for Pakistani and Bangladeshi women and below the UK average for women of Chinese background. The existence of additional factors influencing fertility is the most apparent and the most pronounced for these groups, and seems to operate largely independently

14 As of 2011, total fertility dropped to 1.6 for women with a degree, but remained at 3.3 for illiterate women, 3.0 for women with less than a primary level of education, and 2.5 for those with a primary level of education. Source: Government of India, table 'TFR by educational level of women 2006-2011', accessed on 12 Sept 2017 at https://data.gov.in/keywords/age-specific-fertility-rates. 
of women's qualification levels. Sample size restrictions prevented me from investigating the educational gradient in fertility in more detail, and the broad groups used here may hide some differences in fertility across groups. However, alternative classifications were examined (e.g. degree against A-level and below), and did not alter the results presented here. Future analyses of larger samples would help to clarify to what extent the additional (unexplained) factors shaping fertility differentials are correlated with education.

While selectivity may have affected the educational composition of Chinese migrants, these migrants were still found to have lower fertility levels when the estimates were decomposed by educational category. These results therefore suggest that the characteristic hypothesis alone cannot explain the fertility patterns of Chinese immigrant and second-generation women. According to the socialisation hypothesis, low fertility norms in contemporary China ${ }^{15}$ should have contributed to the very low fertility levels observed among immigrant Chinese women. However, this hypothesis does not explain the depressed period fertility found among secondgeneration Chinese women, which should have been closer to the UK average, especially after educational composition was accounted for. Similarly, consistent with the socialisation hypothesis, the larger family norms in the countries of origin may have helped to sustain the higher fertility levels found among immigrant women from Pakistan and Bangladesh. But given the remaining differentials that were observed after decomposing the fertility of second-generation women by educational attainment, future research is needed to explain the interplay of the transnational ties and the cultural and structural factors that influence the childbearing behaviour of the daughters of immigrants.

\subsection{Transnational cultural ties, social mobility, and minority status}

In the United States, the socio-economic success of second-generation American Asians, especially those of East Asian origin, has framed the upward path of the segmented assimilation theory. The success of these groups has been largely attributed to the very high levels of educational attainment favoured by their cultural background and community ties, including a strong emphasis on education and on the self-organisation of community-based educational support (Zhou and Kim 2006; Zhou 2008; Byun and Park 2012). Instead of the 'tiger mum' model of high parental educational expectations as an inherited cultural trait, Lee and Zhou (2015) emphasised the role of the 'hyper selectivity' of well-educated Chinese migrants, and of the community-based educational organisations and social network supports that benefit the whole community.

The high educational attainment levels of British Chinese women may resemble the US model, but do not explain their depressed fertility, which persists after

15 Fertility has been decreasing since the 1970s in China and the introduction of family policy programmes culminating in the well-known 'one-child policy' have recently been relaxed. 
controlling for educational level. Transnational ties and the influence of childbearing norms in China - especially in urban China, where childlessness is increasingly common, and having one child only has become the institutionalised norm over the last 40 years - might explain the depressed fertility found among British Chinese women. Conversely, the minority status hypothesis offers a plausible alternative explanation. According to Goldscheider and Uhlenberg (1969), in response to a perceived ethnic penalty, segments of a minority population may reduce their family size to facilitate their social mobility. Previous work for the UK has found that the returns to educational attainment in terms of wages are generally lower for minority groups than for the White British group (Heath et al. 2008). However, this is less the case for second-generation women of Indian or Chinese descent, with the latter group having the highest employment probability (Dustmann and Theodoropoulos 2010). It is plausible that the very low fertility among British Chinese women is a compensating factor favouring professional achievement. Tran (2016) found that delayed childbearing among Chinese migrants in New York facilitated their children's access to high-quality public schools, and noted that second-generation Chinese American "believe they must try harder to succeed in the American context" (p. 2402). ${ }^{16}$

\section{Concluding remarks}

This study documents an educational gradient in the fertility patterns of ethnic minorities in the UK, and challenges some of the discourses on their cultural distinctiveness. Nonetheless, the remaining unexplained variation also shows that additional factors shape fertility behaviours, independent of women's educational attainment, and with differences across groups. It remains unclear to what extent the low fertility observed among second-generation women of Chinese heritage is a means to overcome the ethnic penalty on the labour market, and/or is a mechanism for regaining the social status their parents lost after migration (see Platt 2005; Ichou 2014). The potential role of transnational influences and ties adds further complexity to the relationships between childbearing, education, ethnicity, and generation in the UK that were explored in this paper, and calls for more mixed-methods investigations of this intersectional process. The higher proportions of British Pakistani and Bangladeshi women with a degree, but also other unmeasured factors, are resulting in a smaller fertility gap for the second than for the first generation when compared to national fertility levels. Consistent with these observed changes is the increasing sense of agency around childbearing among British Pakistani women, as discussed by Hamphire et al. (2012), which is associated with more educational and work options. When interpreting the fertility of immigrants and their children,

16 Earlier, Espenshade and Ye (1994) explained intra-group fertility differentials among Chinese American women as differential responses to structural discrimination. 
the emphasis is often on the remaining distance between minority groups and the majority population. More emphasis on the group-specific patterns and the withingroup dynamics that shape childbearing behaviour, over time and across generations, would help us gain a better understanding of the socio-demographic trajectories of immigrants and their children.

\section{Acknowledgments}

This work was supported by the Oxford University Press John Fell fund. The writing of the paper was partly supported by an Oxford Returning Carer Award and a UK Economic and Social Research Council grant (Ref: ES/N01877X/1) to the author. I am extremely grateful to Dr Lorraine Waller for her support in preparing the data on education and births by educational attainment. I am also thankful for the constructive comments from the audiences at the BSPS conference 2013 (UK, Swansea) and the PAA conference 2014 (US, Boston), where the results were first presented; and for the helpful feedback from the anonymous reviewers and editors of this issue.

\section{References}

Adsera, A. and A. Ferrer 2014. Fertility adaptation of Child migrants to Canada. Population Studies 68(1): 65-79.

Andersson, G., L. Persson and O. Obucina 2017. Depressed fertility among descendants of immigrants in Sweden. Demographic Research 36: 1149-1184.

Basu, A. M. 2002. Why does education lead to lower fertility? A critical review of some of the possibilities. World Development 30(10): 1779-1790.

Bean, F. D. and J. P. Marcum 1978. Differential fertility and the minority status hypothesis: An assessment and review. In The demography of racial and ethnic groups, eds F. D. Bean and W. Parker Frisbie, 189-211. New York: Academic Press.

Bean, F. D. and M. Tienda 1987. The Hispanic population of the United States. Russell Sage Foundation, 456 pages.

Becker, G. S. and H. G. Lewis 1973. On the interaction between the quantity and quality of children. Journal of Political Economy 81(2): S279-S288.

Berrington, A. and S. Pattaro 2014. Educational differences in fertility desires, intentions and behaviour: A life course perspective. Advances in life Course Research 1-18. DOI: 10.1016/j.alcr.2013.12.003.

Berrington, A., J. Stone and E. Beaujouan 2015. Educational differences in timing and quantum of childbearing in Britain: A study of cohorts born 1940-1969. Demographic Research 37(1): 89-123. DOI: 10.4054/DemRes.2015.33.26.

Bourdieu, P. 1974. The school as a conservative force. In Contemporary research in the sociology of education, ed. T. Eggleston. London: Methuen. 
Byun, S. and H. Park 2012. The academic success of East Asian American youth: The role of shadow education. Sociology of Education 85(1): 40-60.

DOI: $10.1177 / 0038040711417009$.

Coleman, D. and S. Dubuc 2010. The fertility of ethnic minority populations in the United Kingdom, 1960s-2006. Population Studies 64(1): 19-41.

Dubuc, S. 2009. Application of the Own-Children method for estimating fertility of women by ethnic groups in the UK. Journal of Population Research 26(3): 207-225.

Dubuc, S. 2012. Immigration to the UK from high-fertility countries: Intergenerational adaptation and fertility convergence. Population and Development Review 38(2): 353-368.

Dubuc, S. 2016. Immigrants and ethnic fertility convergence in the UK: The role of global fertility transition and intergenerational social integration. In Changing population of Britain, eds T. Champion and J. Falkingham. Rowan Littlefield International Editions.

Dubuc, S. 2017. Fertility of immigrants. In Encyclopedia of Migration, eds F. Bean and S. Brown. Springer Science editions.

Dubuc, S. and J. Haskey 2010. Ethnicity and fertility in the UK. In Understanding population trends and processes, Volume 3: Ethnicity and integration, Chapter 4, eds J. Stilwell and M. van Ham, 63-82.

Dubuc, S. and L. Waller 2014. Reproductive choices and education of immigrant and second generation women in the UK. Paper at the Annual Meeting of the Population Association of America (PAA) conference, Boston, 1-3 Mai 2014. http://paa2014.princeton.edu/abstracts/ 142643, accessed 20 August 2017.

Dustmann, C. and N. Theodoropoulos 2010. Ethnic minority immigrants and their children in Britain. Oxford Economic Papers. Oxford University Press, p. 25. DOI: $10.1093 /$ oep/gpq004.

Goldscheider, C. and P. R. Uhlenberg 1969. Minority group status and fertility. American Journal of Sociology 74(4): 361-373.

Goldstein, S. and A. Goldstein 1983. Migration and fertility in Peninsular Malaysia. A Rand Note, Prepared for The Agency for International Development, [N-1860-AID]. http://www.rand.org/pubs/notes/N1860.html.

Goldthorpe, J. H. 1996. Class analysis and the reorientation of class theory: The case of persisting differentials in educational attainment. The British Journal of Sociology, Special Issue for Lockwood 47(3): 481-505.

Gordon, M. M. 1964. Assimilation in American life the role of race, religion, and national origins. New York: Oxford University Press, p. 276.

Espenshade, T. J. and W. Ye 1994. Differential fertility within an ethnic-minority - the effect of trying harder among Chinese-American women. Social Problems 41(1): 97-113.

Hamel, C. and A. Pailhé 2015. Avoir des enfants en contexte migratoire. In Trajectoires et origines. Enquête sur la diversité des populations en France, eds C. Beauchemin, C. Hamel and P. Simon, 323-352. Paris: Collection Grandes enquête, INED.

Hampshire, K., M. Blell and B. Simpson 2012. Navigating new socio-demographic landscapes: Using anthropological demography to understand the 'persistence' of high and early fertility among British Pakistanis. European Journal of Population 28: 39-63.

Heath, A., C. Rothon and K. Elina 2008. The second generation in Western Europe: Education, unemployment and occupational attainment. Annual Review of Sociology 34: 211-235. 
Ichou, M. 2014. Who they were there: Immigrants' educational selectivity and their children's educational attainment. European Sociological Review 11-29. DOI: 10.1093/esr/jcu071.

Jivraj, S. and L. Simpson (eds) 2015. Ethnic identity and inequalities in Britain. The dynamics of diversity. Policy Press, p. 238.

KC, S., B. Barakat, A. Goujon, V. Skirbekk, W. Sanderson and W. Lutz 2010. Projection of populations by level of educational attainment, age, and sex for 120 countries for 2005-2050. Demographic Research 22(15): 383-472.

Kulu, H. and A. González-Ferrer 2014. Family dynamics among immigrants and their descendants in Europe: Current research and opportunities. European Journal of Population 30(4): 411-435.

Kulu, H., T. Hannemann, A. Pailhé, K. Neels, S. Krapf and A. Gonzalez-Ferrer Gunnar Andersson 2017. Fertility by birth order among the descendants of immigrants in selected European countries. Population and Development Review 43(1): 30-60.

Lee, J. and M. Zhou 2015. The Asian American achievement paradox. New York: Russell Sage Foundation.

Lessard-Phillips, L. 2008. An examination of the educational attainments of secondgeneration immigrants in the United Kingdom. In Ethnicity and Social divisions, Chapter seven, eds K. Hallden, E. le Grand and Z. Hellgren, 171-208. Cambridge Scholars Publishing.

Mayer, J. and R. T. Riphaln 2000. Fertility assimilation of immigrants: Evidence from count data models. Journal of Population Economics 13: 241-261.

Meurs, D., P. A. Puhani and F. Von Haaren 2015. Number of siblings and educational choices of immigrant children: Evidence from first- and second-generation immigrants. Working paper, IZA DP No. 9106.

Milewski, N. 2010. Fertility of immigrants. A two-generational approach in Germany. Demographic research monographs series. Berlin Heidelberg: Springer, p. 176.

Modood, T. 2005. The educational attainment of ethnic minorities in Britain. In Ethnicity, social mobility and public policy: Comparing the US and UK, eds G. C. Loury, T. Modood and S. M. Teles, 288-308. New York: Cambridge University Press.

Morgan, S. P., S. C. Watkins and D. Ewbank 1994. Generating Americans: The fertility of the foreign-born in the US, 1905-10. In After Ellis Island: Newcomers and natives in the 1910 census, ed. S. Watkins. New York: Russell Sage Foundation.

Ní Bhrolcháin, M. and É. Beaujouan 2012. Fertility postponement is largely due to rising educational enrolment. Population Studies 66(3, November): 311-327.

Parrado, E. A. 2011. How high is Hispanic/Mexican fertility in the United states? Immigration and tempo considerations. Demography 48(3): 1059-1080.

Pew Research Center 2015. Childlessness falls, family size grows among highly educated women. PEW Research Centre report, Washington, DC, p. 17.

Platt, L. 2005. Migration and social mobility. The life chances of Britain's minority ethnic communities. Joseph Rowntree Foundation report, Policy Press, p. 44.

Portes, A. and M. Zhou 1993. The new second-generation: Segmented assimilation and its variants. The Annals of the American Academy of Political and Social Sciences 530: 74-96. 
Rees, P. 2008. What happens when international migrants settle? Projections of ethnic groups in United Kingdom regions. In International migration in Europe: Data, models and assessment, eds J. Raymer and F. Willekens, 329-358. London: Wiley.

Rendall, M., C. Couvet, T. Lappegard, I. Robert-Bobée, M. Ronsen and S. Smallwood 2005. First births by age and education in Britain, France and Norway. Population Trends 121: 27-34.

Rindfuss, R. R., S. P. Morgan and K. Offutt 1996. Education and the changing age pattern of American fertility: 1963-89. Demography 33(3): 277-290.

Robards, J. and A. Berrington 2015. The fertility of recent migrants to England and Wales. Demographic Research 34: 1037-1052. DOI: 10.4054/DemRes.2016.34.36.

Scott, K. and M. Stanfors 2011a. Second Generation Mothers - Do the children of immigrants adjust their fertility to host country norms? In Demographic aspects of migration, eds T. Salzmann, B. Edmonston and J. Raymer, 123-152.

Scott, K. and M. Stanfors 2011b. The transition to parenthood among the second generation: Evidence from Sweden, 1990-2005. Advances in Life Course Research 16(4): 190-204.

Sobotka, T. and W. Lutz 2009. Misleading policy messages from the period TFR: Should we stop using it? European Demographic Research Papers, p. 43.

Stephen, H. E. and F. D. Bean 1992. Assimilation, disruption and the fertility of MexicanOrigin women in the United Sates. International Migration Review 26(1): 67-88.

Stichnoth, H. and Yester M. 2016. Cultural influences on the fertility behaviour of first and second generation immigrants in Germany. Journal of Demographic Economics 82: 281-314.

Toulemon, L. 2004. Fertility among immigrant women: New data, new approach. Population and Societies 400: 1-4.

Tran, V. C. 2016. Ethnic culture and social mobility among second-generation Asian Americans. Ethnic and Racial Studies 39(13): 2398-2403.

Van de Kaa, D. J. 1987. Europe's second demographic transition. Population Bulletin 42(1).

Waller, L., A. Berrington and J. Raymer 2014. New insights into the fertility patterns of recent Polish migrants in the United Kingdom. Journal of Population Research 31(2): 131-150. DOI: 10.1007/s12546-014-9125-5.

Zhou, M. 2008. The ethnic system of supplementary education: Nonprofit and for-profit institutions in Los Angeles Chinese immigrant community. In Toward positive youth development: Transforming schools and community programs, eds M. Shinn and H. Yoshikawa, 229-251. New York: Oxford University Press.

Zhou M. and S. S. Kim 2006. Community forces, social capital, and educational achievement: The case of supplementary education in the Chinese and Korean immigrant communities. Harvard Educational Review 76(1): 1-29. 


\section{Appendix}

\section{A.1 Ethnic categories in the British 2001 census and in surveys}

Ethnicity is self-reported by survey respondents, but the responses are shaped by a predefined nomenclature. The 2001 classification used here had two levels. Level 1 classified individuals into five broad groups: White, Mixed, Asian or Asian British, Black or Black British, Chinese, and an additional group Other. Level 2 provided a finer classification nested within Level 1. This more detailed classification distinguished between 16 ethnic groups. The White population was subdivided into White British, White Irish, and White Other. There were also four Mixed ethnic sub-groups (White and Black Caribbean, White and Asian, White and Black African, Other Mixed), four Asian British or Asian sub-groups (Indian, Pakistani, Bangladeshi, Other Asian), three Black or Black British subgroups (Black Caribbean, Black African, Other Black). The Chinese group and the remaining group Other were not subdivided further.

\section{A.2 Counts of women aged 15-49 by category and study period}

\begin{tabular}{|c|c|c|c|c|c|c|c|c|c|}
\hline \multirow[b]{2}{*}{$\begin{array}{l}\text { Ethnic } \\
\text { category }\end{array}$} & \multirow{2}{*}{ 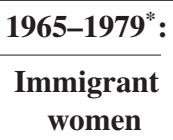 } & \multicolumn{4}{|c|}{$1987-2010^{* *}$ : all ethnic group } & \multicolumn{4}{|c|}{ 1987-2010: UK-born women } \\
\hline & & All & Degree & A-Level & GCSE & All & Degree & A-Level & GCSE \\
\hline Indiar & 41,110 & 96,358 & 44,730 & 14574 & 37,054 & 31,544 & 15,1 & 6,626 & 9,785 \\
\hline Pakistan & 16,3 & 1 & 15,8 & & 51 & 23,6 & & 5,1 & 11,242 \\
\hline Bang & & & & & 15,821 & 4,3 & & 1,086 & 2,176 \\
\hline Chinese & 6,921 & 23,628 & 13,782 & 2,690 & 7,156 & 3,623 & 2,222 & 575 & 826 \\
\hline
\end{tabular}

Sources: *LFS 1979, 1983 to 1992 ; ${ }^{* *}$ LFS-APS data 2001-2010.

\section{A.3 Counts of women aged 25-29 by ethnic category over the 1987-2010 period}

\begin{tabular}{lcrr}
\hline & $\begin{array}{l}\text { Degree/Higher } \\
\text { education }\end{array}$ & $\begin{array}{l}\text { A-level } \\
\text { (equiv.) }\end{array}$ & $\begin{array}{l}\text { GCSE } \text { and } \\
\text { below }\end{array}$ \\
\hline White British & 212,338 & 114,964 & 275,601 \\
(British) Indian & 9332 & 2145 & 5236 \\
(British) Chinese & 2612 & 324 & 939 \\
(British) Pakistani and Bangladeshi & 4175 & 2129 & 9730 \\
\hline
\end{tabular}

Source: LFS-APS data 2001-2010. 
